\title{
Superficial Peroneal Nerve Thickening as an Early Diagnostic Sign in Leprosy
}

\author{
E. P. VAIDYANATHAN AND S. I. VAIDYANATHAN
}

Bababaghi Leprosy Sanatorium, Tabriz, Iran

\begin{abstract}
Clinical examination of 1020 persons in a region of India in which leprosy is endemic revealed thickening of one or both superficial peroneal nerves in 54 persons, 19 having previously received treatment for leprosy, whether full or incomplete (old cases), and 35 never having been treated (new cases). Biopsies of thickened superficial peroneal nerves showed that of 33 symptom-free new patients, 18 had diagnostic histological changes $(54.5 \%)$, and a plea is made that screening examinations for leprosy should always include palpation of superficial peroneal nerves, for subsequent nerve biopsies are likely to provide early diagnostic evidence in more than $50 \%$ of cases.
\end{abstract}

\section{Introduction}

This study was carried out in 1969 at Hemerijckx Leprosy centre Polambakkam, India, a centre which covers a total population of 658,311 , of which 537,349 have been examined. The total number of registered leprosy patients was 26,743, and at the time of this study, 15,882 were under treatment. Kandaswami (1968) has reported from this centre that of 10,868 discharged patients, 462 relapsed (4.3\%). During the first 9 months of 1969 377 new cases were registered, of which 103 were from contact houses and the remaining 274 gave no history of contact with leprosy.

TABLE 1

New cases registered between 1.1.1969 and 30.9.1969

\begin{tabular}{lc}
\hline Type of leprosy & Number of cases \\
\hline Lepromatous & 19 \\
Non-lepromatous & 325 \\
Unclassified & 33 \\
$\quad$ Total & 377 \\
\hline
\end{tabular}

All patients were examined at roadside clinics in bright sunlight and when thickening of one or both superficial peroneal nerves was palpated, the patient was transferred to the centre for nerve biopsy. Six skin smears (slit smear) were made in addition, the sites being ear lobes, forehead, cheeks, and back. The patients who were examined included new cases, persons who had previously been treated for leprosy and had been discharged, and those who 
had defaulted on treatment. Of the new cases, some presented with dermatoses such as scabies and ringworm, some had skin lesions of leprosy and/or skin anaesthesia and some had no symptoms. Of a total of 1020 persons examined $54(5.3 \%)$ were found to have thickening of superficial peroneal nerves, and these patients were selected for our study.

\section{Investigations}

Of the 54 patients ( 35 new cases and 19 old cases) 5 had symptoms related to skin or nerves and 49 were symptom free. Table 2 shows how these findings differed as between new and old cases.

TABLE 2

Presence or absence of symptoms

\begin{tabular}{lccc}
\hline Cases & With symptoms & Without symptoms & Total \\
\hline New cases & 2 & 33 & 35 \\
Old cases & 3 & 16 & 19 \\
Total & 5 & 49 & 54 \\
\hline
\end{tabular}

Biopsy of one superficial peroneal nerve was carried out in all 54 patients. This nerve is purely sensory and therefore can safely be biopsied. Our method was: through a small incision of about $2 \mathrm{~cm}$ long the nerve was identified at the lower third of the leg on the lateral aspect and a complete segment of about $1 \mathrm{~cm}$ of the nerve was taken for biopsy.

Histological examination revealed cellular infiltration in 9, cellular infiltration plus acid-fast bacilli in 20 , and normal histology in 25 . Table 3 shows how these findings differed as between new and old cases.

TABLE 3

Histological studies of superficial peroneal nerves

\begin{tabular}{lcccc}
\hline & $\begin{array}{c}\text { Cellular } \\
\text { infiltration } \\
\text { without } \\
\text { A.F.B. }\end{array}$ & $\begin{array}{c}\text { Cellular } \\
\text { infiltration } \\
\text { and } \\
\text { A.F.B. }\end{array}$ & N.A.D. & Total \\
\hline $\begin{array}{l}\text { New cases } \\
\text { without symptoms }\end{array}$ & 4 & 14 & 15 & 33 \\
$\begin{array}{l}\text { New cases with } \\
\text { symptoms }\end{array}$ & 2 & - & - & 2 \\
$\begin{array}{l}\text { Old cases } \\
\text { without symptoms }\end{array}$ & 2 & 4 & 10 & 16 \\
$\begin{array}{l}\text { Old cases } \\
\text { with symptoms } \\
\text { Total }\end{array}$ & 1 & 2 & - & 3 \\
\hline
\end{tabular}




\section{Discussion}

It can be seen from the above table that of 49 patients without symptoms (33 new and 16 old cases), 24 showed diagnostic changes in the superficial peroneal nerves $(48.9 \%)$ and of 33 new patients without symptoms, 18 showed diagnostic changes (54.5\%). Eight of 15 patients who had no symptoms were followed-up for 2 years and were unchanged at the end of that time, and it is probable that the palpable nerve thickening could have been related to trauma as the location of this nerve makes it liable to repeated trauma. Of the 33 symptom-free new patients, 18 of whom had leprous changes within nerves, none developed symptoms (skin lesions and/or anaesthesia) over the next 2 years. Skin smears of the 35 new patients were negative for acid-fast bacili, and only one of the 35 was from a contact house.

It is our conviction that screening examinations for leprosy should always include palpation of superficial peroneal nerves. Subsequent nerve biopsies are likely to give irrefutable evidence of leprosy in over $50 \%$ of cases.

\section{Ref erences}

Kandaswami, V. (1968). The study of relapse in leprosy in a mass control scheme with DDS at Polambakkam Leprosy Centre. Paper read at 9th International Leprosy Congress, London, September 1968. 